\title{
Voltage stability assessment for distributed generation in islanded microgrid system
}

\author{
Saleh A. Gareh ${ }^{1}$, B. C. Kok ${ }^{2}$ \\ ${ }^{1} \mathrm{~A}$ PhD candidate atFaculty of Electrical and Electronic Engineering, Universiti Tun Hussein Onn Malaysia, 86400 Parit Raja, Batu \\ Pahat, Johor, Malaysia \\ ${ }^{2}$ Department of Electrical Power Engineering, Faculty of Electrical and Electronic Engineering, Universiti Tun Hussein Onn Malaysia, \\ 86400 Parit Raja, Batu Pahat, Johor, Malaysia
}

Email address:

salehgareh@gmail.com (S. A. Gareh), bc.kok@uthm.edu.my (B. C. Kok)

To cite this article:

Saleh A. Gareh, B. C. Kok. Voltage Stability Assessment for Distributed Generation in Islanded Microgrid System. Journal of Electrical and Electronic Engineering. Vol. 2, No. 1, 2014, pp. 22-27. doi: 10.11648/j.jeee.20140201.14

\begin{abstract}
The increasing energy demands are stressing the generation and transmission capabilities of the power system. Distributed generation (DG), which generally located in distribution systems, has the ability to meet some of the growing energy demands. However, unplanned application of individual distributed generators might cause other technical problems. The Microgrid concept has the potential to solve major problems arising from large penetration of DG in distribution systems. This project proposes a simulation approach to study voltage stability index (VSI) and voltage stability analysis in Microgrid system for the improvement of the dynamic voltage stability in a microgridin case of the dynamic voltage in sufficiency. A model of IEEE-14 Bus System has been presented as a case study of an islanded microgird system. This project also presented line voltage stability index analysis which accurately calculates voltage stability analysis at each transmission line and precisely predicts voltage collapse on power systems. A formula to calculate VSI has been derived and applied on two cases on the system. To show the effectiveness of the proposed microgrid system, this approach is implemented in a microgrid system (14-bus, 20 lines) in PSAT, which is a MATLAB toolbox environment. The test system has four diesel DGs and a wind turbine connected with eleven constant loads. A dynamic simulation of the test system is carried out for the cases for various disturbances. Islanded mode of operation is considered in this study. FVSI and voltage stability analysis were successfully implemented and analyzed.
\end{abstract}

Keywords: Voltage Stability, Distributed Generation (DG), Voltage Stability Index (VSI), Microgrid System, PSAT

\section{Introduction}

Since the increase of power demand is stressing the transmission and generation system capabilities that might lead to frequent power outages, engineers around the world are developing different methods to improve the reliability, protection and security of the electrical power system. These frequent power outages due to the overloaded grid will costs millions of Dollars per year. Newer technologies authorize the production of electrical energy in an efficient, reliable and secure way, causing fewer damages to the environment. One of the significant solutions is to build generation closer to the power consumption areas. This is known as distributed generation (DG) [1].

The large interconnected power system made the electricity distribution reliable and economical. This interconnection of multi areas exposed the entire system to be more vulnerable to various stability problems [2] sector have given major scope for employment of DG resources that will boost the system performance [14]. Usually, the main concentration of generation stations is near to the load or biggest demand of power. If this condition does not happen and the load is far away from the generation stations, consumers will face outage problems and drop in voltage as well [3].

PSAT is a Matlab toolbox for electric power system analysis and control. The command line version of PSAT is also GNU Octave compatible. PSAT includes power flow, continuation power flow, optimal power flow, small signal stability analysis, and time domain simulation. All operations can be assessed by means of graphical user interfaces (GUIs) and a Simulink-based library provides an 
use friendly tool for network design [12].

\section{Concept of Voltage Stability}

Voltage stability analysis is currently one of the most significant fields of research in the power systems area [11]-[13]. In the last few years, many contributions to a better knowledge of the various aspects of voltage problems have been reported in the literature, where the problem has been explored from many different points of view [4]. Voltage collapse in addition, has been an active subject of research for years [5]- [6].

\section{Distributed Generation (DG)}

Various technologies are being developed to generate electrical energy close to the consumption areas (load centers). This modality is called generation IN-SUIT, disperse generation or distributed generation [7]. Distributed generation is a small scale generation or storage of electrical energy at the customer side, which permits the option of selling and buying energy to and from the electrical system, while taking advantage of the maximum efficiency of energy production [7]. Generally, the capacity range of distributed generation is between $100 \mathrm{~kW}$ and $10 \mathrm{MW}$. Figure 1 shows the differences between centralized generation and distributed generation.

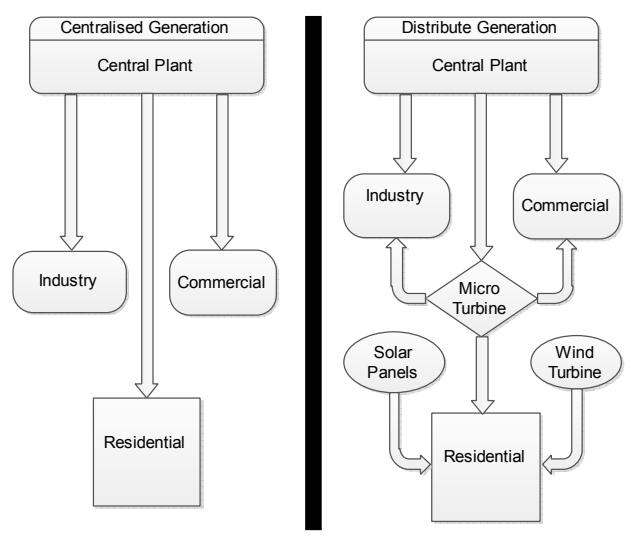

Figure 1. Centralized Generation and Distributed Generation.

\section{Voltage Stability Index (VSI)}

Voltage stability, instability and collapse are well defined in [8] and these issues have been the focus of a great deal of research recently. Dynamic analysis has been used to conduct voltage stability since voltage instability is a dynamic phenomenon. Nevertheless, static voltage stability analysis is widely used in voltage stability research, as static analysis is not overly complex, and requires lower calculation time. Static analysis provides an accurate analysis method for handling mostly short disturbances while dynamic analysis is used to analyze heavy load disturbances [9].

Recently, a number of researchers have been using the voltage stability/instability analysis to calculate voltage collapse as some established new methods, whereas others improved existing methods or proposed some hybrid methods [10].

\section{Fast Voltage Stability Index (FVSI) Calculation}

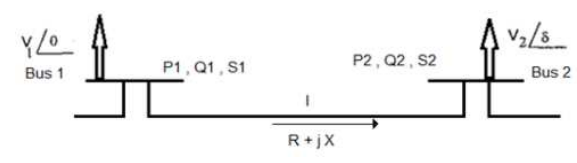

Figure 2. Single line of 2-bus power system model.

$$
F V S I=\frac{4 Z^{2} Q_{j}}{V_{i}^{2} X}
$$

Where:

$Z=$ line impedance

$X=$ line reactance

$Q_{i}=$ reactive power at the receiving end

$V_{i}=$ sending end voltage

The value of FVSI that is evaluated close to 1.00 indicates that the particular line is closed to its instability point which may lead to voltage collapse in the entire system. To maintain a secure condition the value of FVSI should be maintained well below 1.00 [8].

\section{Modelling and Simulations Results}

The Microgrid test case, as shown in Figure 3, has four diesel DGs connected with automatic voltage regulator (AVR) and a wind turbine connected with 14 buses. In addition, some constant power loads are also installed, which presented as PQ buses. Each area of the system is associated with a slack bus, where Bus 1 is picked to be the slack bus of the whole system (generally a V-theta bus that is the angular reference for the system). The Microgrid is not connected to the main grid that makes the system islanded and depends on its DGs.

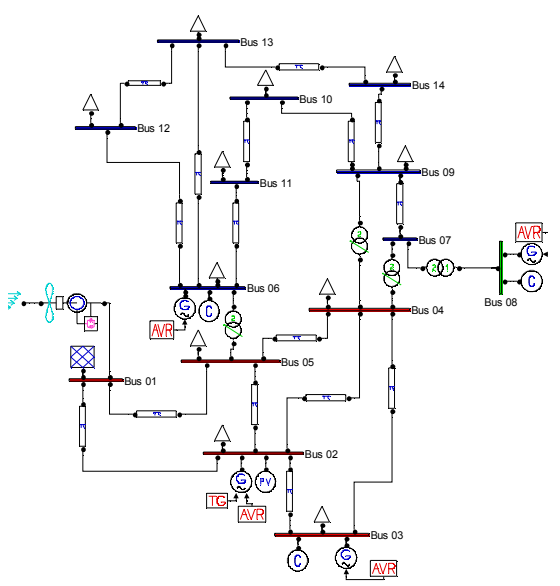

Figure 3. Microgrid test system (IEEE 14 bus test system). 
Table 1 provides FVSI for various changing in reactive power at bus 3 which affects directly the index.

In basecase, line 12 , which is between Bus 3 and Bus 2, is the weakest line in the system where $\mathrm{FVSI}=0.6321$ so that, by increasing the reactive power at Bus 3 to $30 \%$ makes line 12 more sensitive with FVSI $=0.7204$. When the reactive power at Bus 3 increased to $70 \%$, the line 12 become 0.9946 near to 1 which become very close to its instability point which may lead to voltage collapse in the entire system.

Table 1. FVSI with changing in reactive power at Bus 3.

\begin{tabular}{cccccc}
\hline \multicolumn{5}{c}{ VOLTAGE STABILITY INDEX } \\
\multicolumn{1}{c}{ Basecase } & $\mathbf{0 . 2 6 6 p . u}$ & \multicolumn{2}{c}{ Q3=0.3458.u } & \multicolumn{2}{c}{ Q3 $=\mathbf{0 . 4 5 2 2}$.u } \\
\hline line & FVSI & line & FVSI & Line & FVSI \\
1 & 0.0158 & 1 & 0.0158 & 1 & 0.0158 \\
2 & 0.0246 & 2 & 0.0246 & 2 & 0.0246 \\
3 & 0.1318 & 3 & 0.1318 & 3 & 0.1318 \\
4 & 0.0465 & 4 & 0.0465 & 4 & 0.0465 \\
5 & 0.0215 & 5 & 0.0215 & 5 & 0.0215 \\
6 & 0.0688 & 6 & 0.0688 & 6 & 0.0689 \\
7 & 0.0305 & 7 & 0.0306 & 7 & 0.0307 \\
8 & 0.0901 & 8 & 0.0902 & 8 & 0.0906 \\
9 & 0.1412 & 9 & 0.1413 & 9 & 0.1417 \\
10 & 0.0953 & 10 & 0.0954 & 10 & 0.0957 \\
11 & 0.1798 & 11 & 0.2049 & 11 & 0.2829 \\
12 & 0.6321 & 12 & 0.7204 & 12 & 0.9946 \\
13 & 0.0433 & 13 & 0.0433 & 13 & 0.0433 \\
14 & 0.0188 & 14 & 0.0188 & 14 & 0.0188 \\
15 & 0.0103 & 15 & 0.0103 & 15 & 0.0104 \\
16 & 0.0401 & 16 & 0.0401 & 16 & 0.0401 \\
17 & 0.3401 & 17 & 0.3473 & 17 & 0.3726 \\
18 & 0.5193 & 18 & 0.5203 & 18 & 0.5242 \\
19 & 0.0000 & 19 & 0.0000 & 19 & 0.0000 \\
20 & 0.0000 & 20 & 0.0000 & 20 & 0.0000 \\
\hline
\end{tabular}

Table 2. FVSI with changing in reactive power at Bus 9.

\begin{tabular}{cccccc}
\hline \multicolumn{5}{c}{ VOLTAGE STABILITY INDEX } \\
\multicolumn{1}{c}{ Basecase 0.266p.u) } & \multicolumn{1}{c}{ Q9=0.3458p.u } & \multicolumn{2}{c}{ Q9= $\mathbf{0 . 4 5 2 2 p . u}$} \\
\hline line & FVSI & line & FVSI & Line & FVSI \\
1 & 0.0158 & 1 & 0.0158 & 1 & 0.0158 \\
2 & 0.0246 & 2 & 0.0246 & 2 & 0.0246 \\
3 & 0.1318 & 3 & 0.1320 & 3 & 0.1323 \\
4 & 0.0465 & 4 & 0.0465 & 4 & 0.0465 \\
5 & 0.0215 & 5 & 0.0215 & 5 & 0.0215 \\
6 & 0.0688 & 6 & 0.0695 & 6 & 0.0705 \\
7 & 0.0305 & 7 & 0.0313 & 7 & 0.0323 \\
8 & 0.0901 & 8 & 0.0922 & 8 & 0.0954 \\
9 & 0.1412 & 9 & 0.1434 & 9 & 0.1466 \\
10 & 0.0953 & 10 & 0.1255 & 10 & 0.1674 \\
11 & 0.1798 & 11 & 0.1975 & 11 & 0.2225 \\
12 & 0.6321 & 12 & 0.6942 & 12 & 0.7822 \\
13 & 0.0433 & 13 & 0.0433 & 13 & 0.0433 \\
14 & 0.0188 & 14 & 0.0188 & 14 & 0.0188 \\
15 & 0.0103 & 15 & 0.0104 & 15 & 0.0105 \\
16 & 0.0401 & 16 & 0.0401 & 16 & 0.0401 \\
17 & 0.3401 & 17 & 0.3925 & 17 & 0.4695 \\
18 & 0.5193 & 18 & 0.6811 & 18 & 0.9019 \\
19 & 0.0000 & 19 & 0.0000 & 19 & 0.0000 \\
20 & 0.0000 & 20 & 0.0000 & 20 & 0.0000 \\
\hline
\end{tabular}

Where, Table 2 provides FVSI for various changing in power at Bus 9 which affects directly the index.

As the previous case, line 12 , which is between Bus 3 and Bus 2, is the weakest line in the system where FVSI $=0.6321$ so that, by increasing the power at Bus 9 to $30 \%$ that makes line 12 more sensitive with slight increase by $9 \%$ but also line 18 has become $\mathrm{FVSI}=0.6811$ which increased by $24 \%$. When the power at Bus 3 increased to $70 \%$, the line 18 become the weakest line in the system that has increased by $42 \%$ to became FVSI $=0.9019$ which close to 1 which became nearby to its instability point which may lead to voltage collapse in the entire system.

\section{Voltage Stability Analysis of the Microgrid in Islanded Mode}

Apply various disturbances on the system which are listed in Table 3.

Table 3. The disturbances applied on the system.

\begin{tabular}{cll}
\hline Case & Disturbances & Study case \\
\hline 1 & Load switching & Increase load at bus 3 by $10 \%$ \\
& Increase load at bus 14 by $50 \%$ \\
2 & partial line outage & $\begin{array}{l}\text { Line Outage Between Bus 2 And Bus } 3 \\
\text { Line Outage Between Bus 2 and Bus } 3 \\
\text { and reconnect the line } \\
\text { Three phase short circuit fault at Bus } 5\end{array}$ \\
& $\begin{array}{l}\text { Three phase short } \\
\text { circuit fault }\end{array}$ & Three phase short circuit fault at Bus 12 \\
\hline
\end{tabular}

\subsection{Load Switching Disturbance}

\subsubsection{Increase Load at Bus 3 by 10\%}
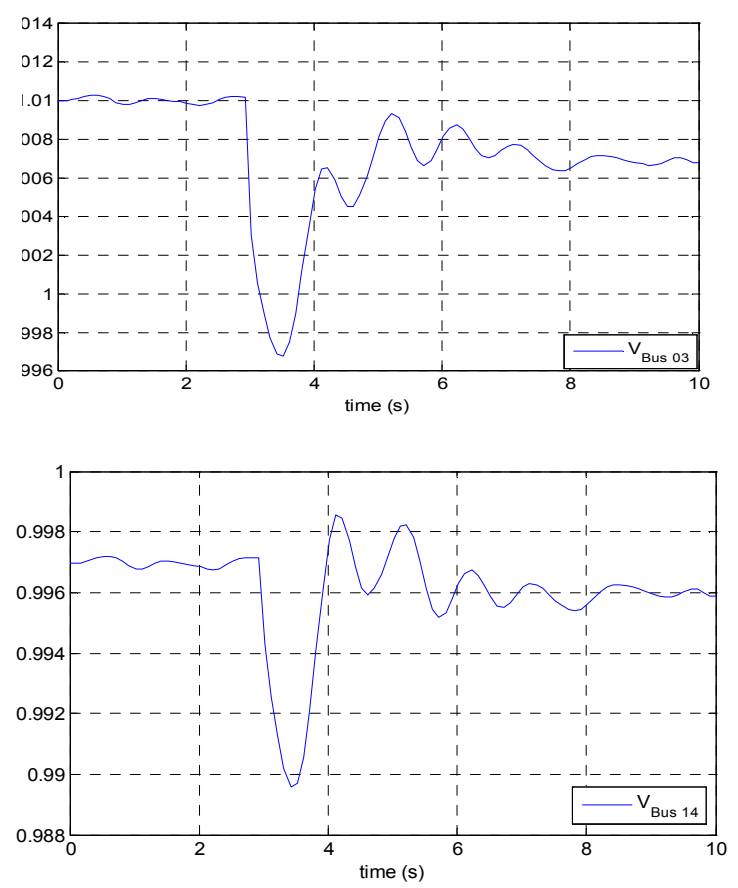

Figure 4. Voltagebus 3,14 fora10\%loadincrementat bus 3. 


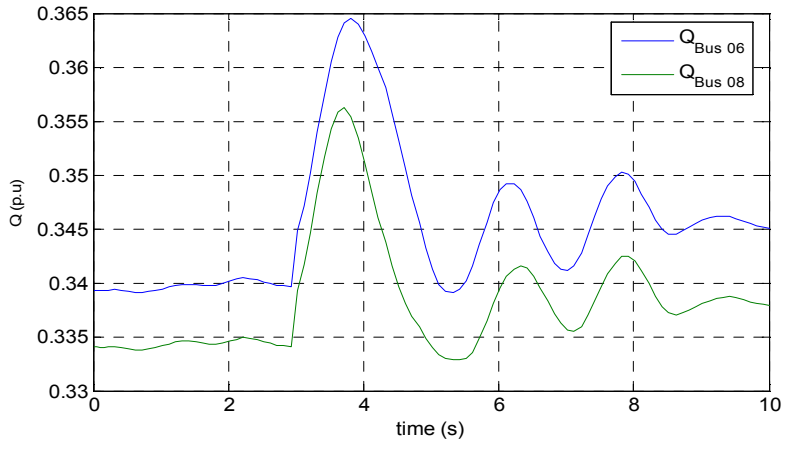

Figure 5. Reactive power at buses 6-8 fora10\%loadincrementat bus 3 .

\subsubsection{Increase Load at Bus 14 by 50\%}

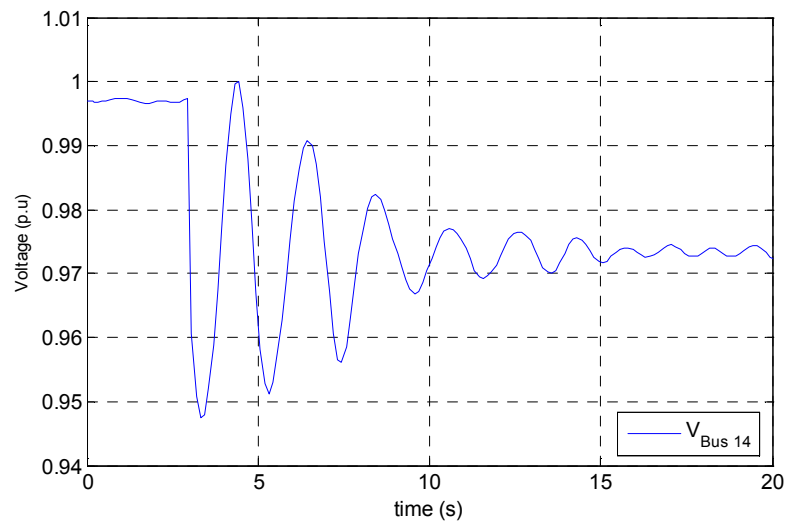

Figure 6. Voltagebus 14, 1 fora50\%loadincrementat bus 14.
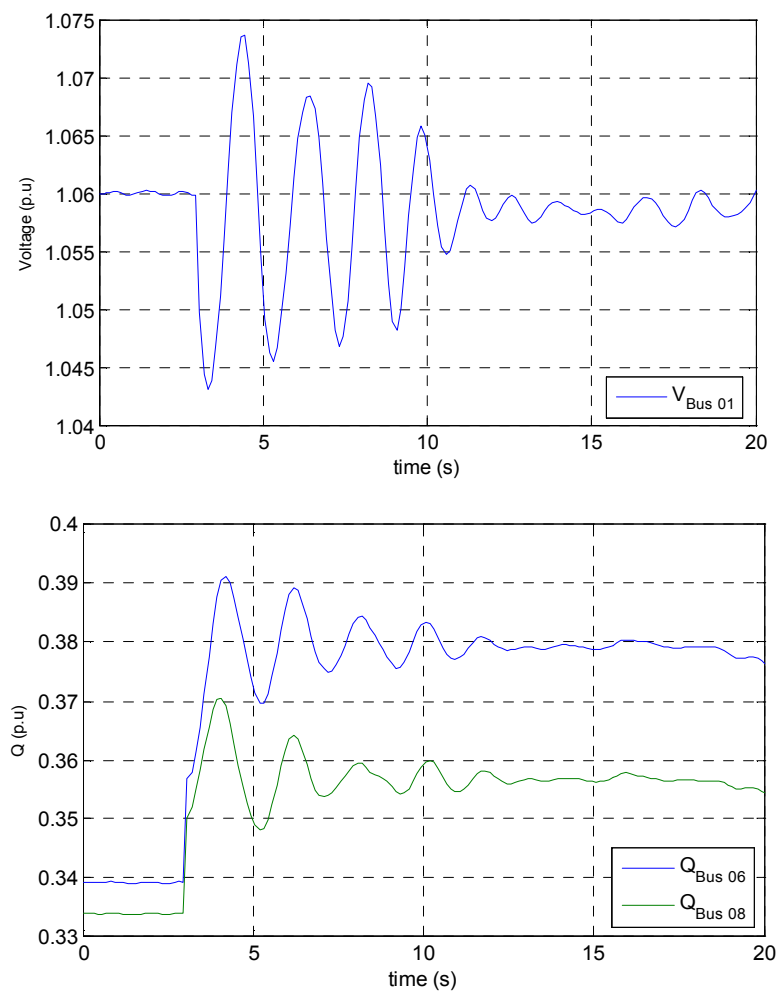

Figure 7. Reactive power at buses 6-8 for a 50\% load increment at bus 14 .

\subsection{Partial Line Outage}

\subsubsection{Line Outage between Bus 2 and Bus 3}
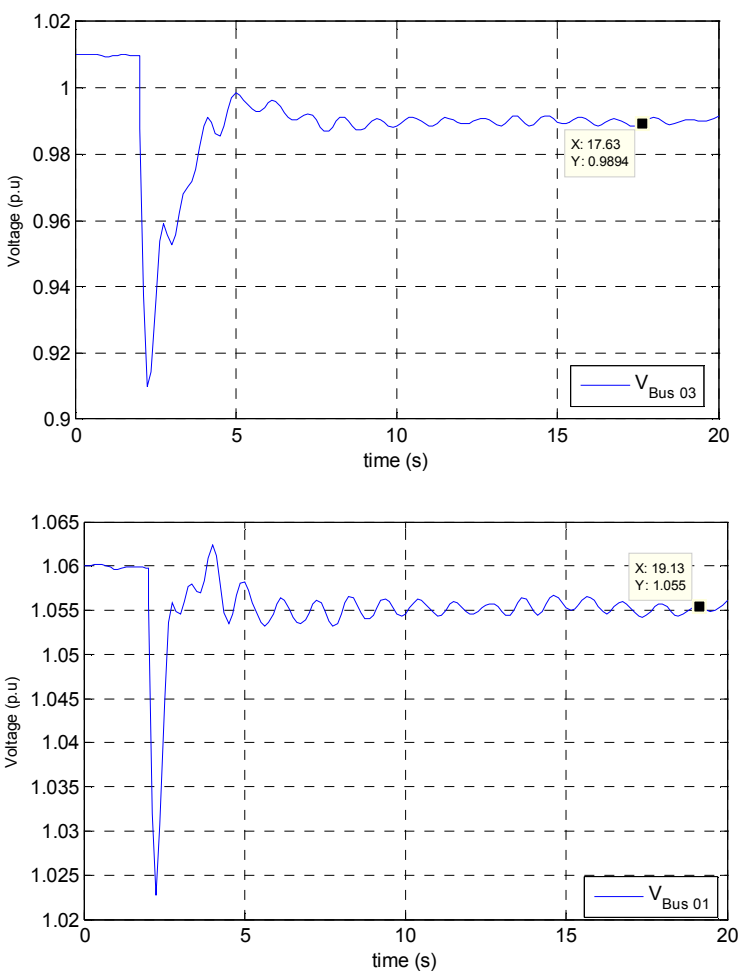

Figure 8. Voltage at bus 3, 1 for a line outage between bus 2 and bus 3 .

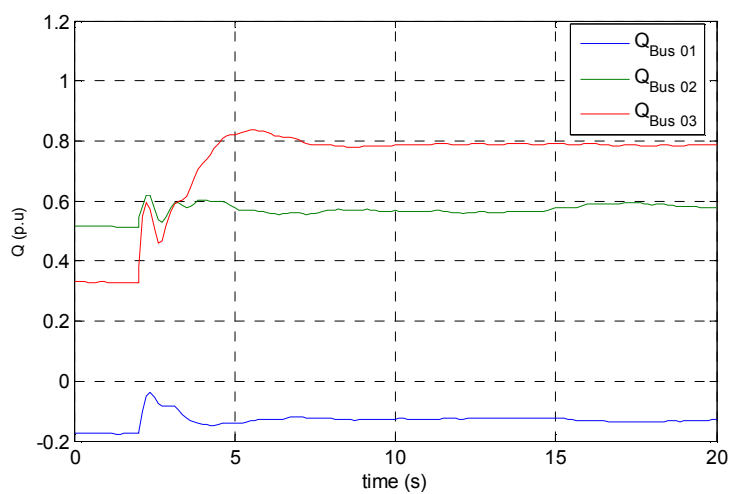

Figure 9. Reactive power at buses 1,2, and 3 for a line outage between bus 2 and bus 3 .

\subsubsection{Line Outage between Bus 2 and Bus 3 and with Reclose}

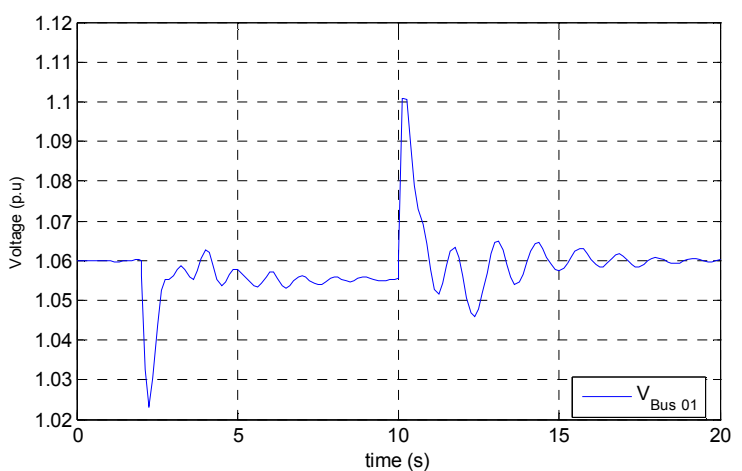




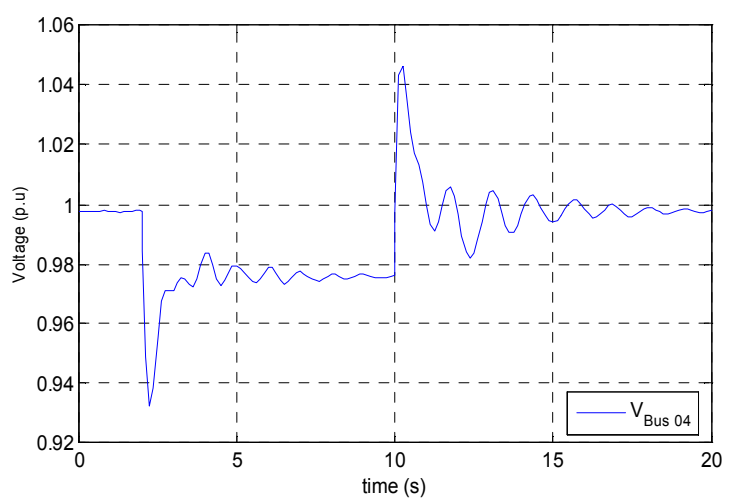

Figure 10. Voltage at bus 1, 4 for a line outage between bus 2 and bus 3 .

\subsection{Fault Analysis}

\subsubsection{Three Phase Short Circuit Fault at Bus 5}
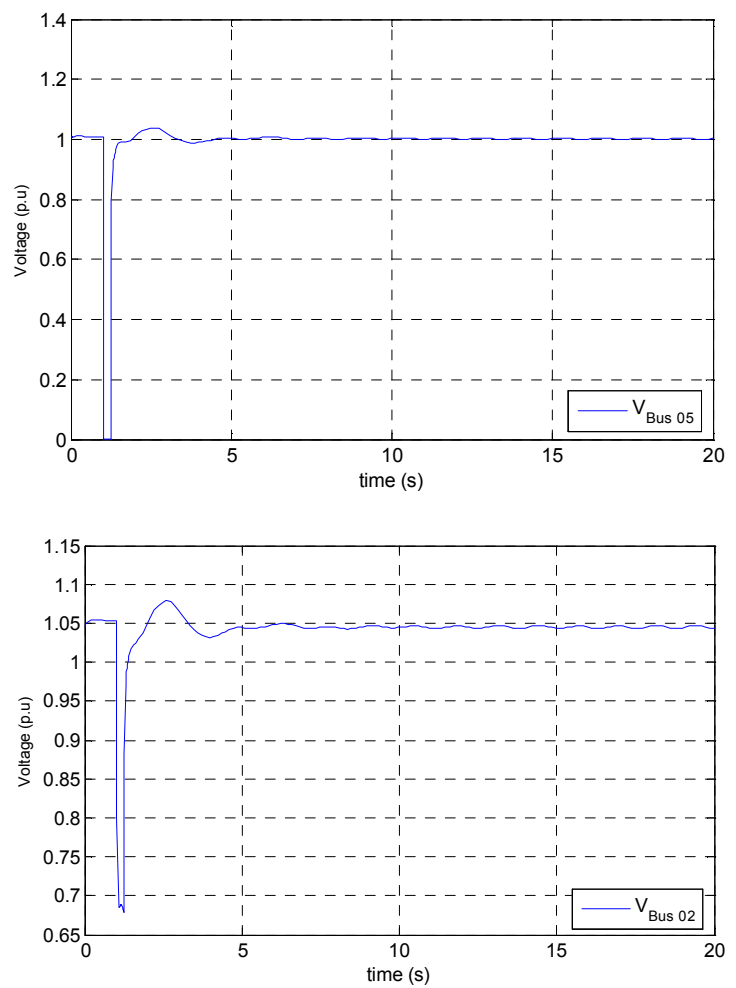

Figure 11. Voltage at bus 5, 2 for a 3-phae short circuit fault at bus 5 .

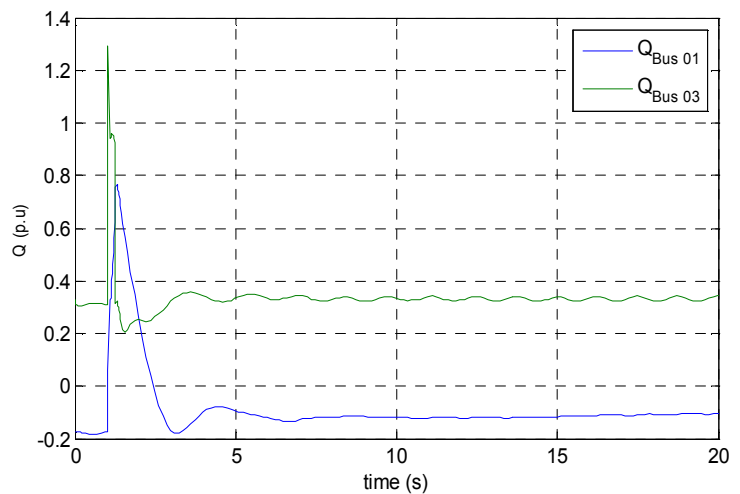

Figure 12. Reactive power at bus 1, 3 for a 3-phase short circuit fault at bus 5 .

\subsubsection{Three Phase Short Circuit Fault at Bus 12}
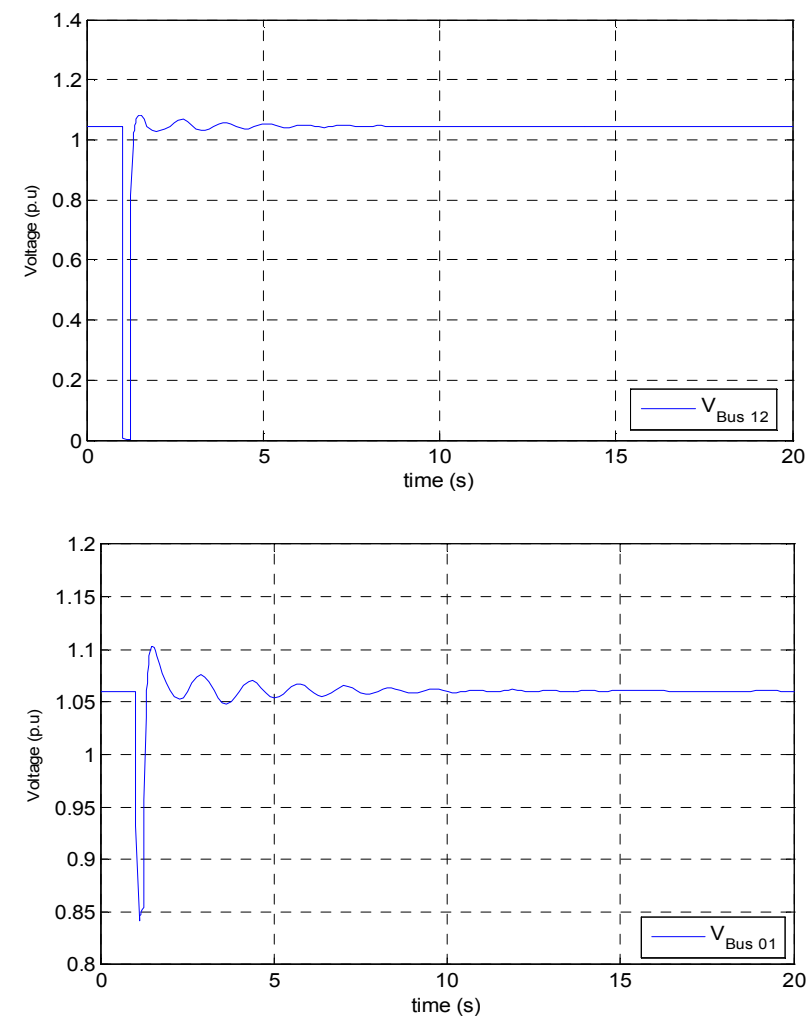

Figure 13. Voltage at bus 12, 1 for a 3-phae short circuit fault at bus 12 .

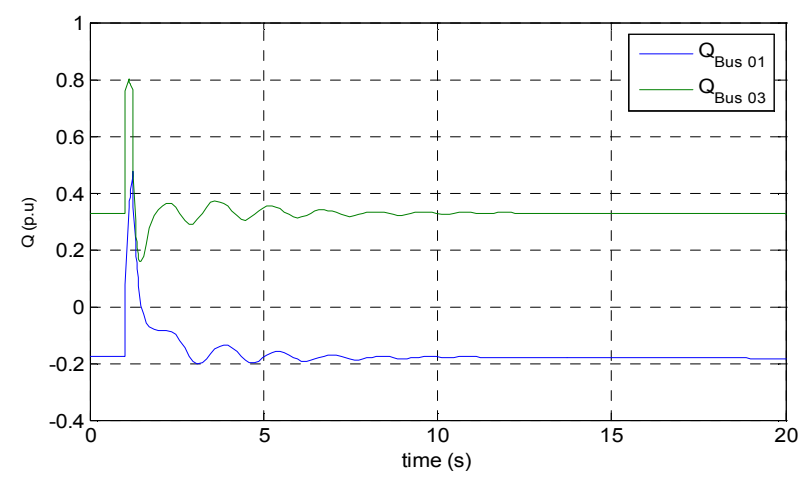

Figure 14. Reactive power at bus 1, 3 for a 3-phase short circuit fault at bus 12.

\section{Conclusion}

In this report, the modeling of a Microgrid with DGs for voltage stability analysis was studied. The PSAT which is MATLAB toolbox was used to simulate several disturbances, including, load switching, line outage, and change in DGs parameters, where three-phase short circuit was applied. Also, the Microgrid system was studied in islanded mode of operation. The results in this thesis compared the voltages at all the load buses and the reactive power generated by the DGs.

Line voltage stability index was studied and illustrated how the reactive power has a significant affected on the index. It is designed to have a direct relationship between 
sending line voltages and line receiving reactive powers, permitting more effective stability analysis, particularly when a power system is subjected to a sudden increase in reactive power.

Simulation results show that, the DGs can significantly improve the voltage profile of the system in both modes of operation during various disturbances. During load switching disturbance, The AVR includes a stability/damping circuit to provide good steady state and transient performance of the generator. So that reactive power is shared between the DGs to support the system during the disturbance. Excessive increasing in power at sensitive buses may lead to outage for the entire system.

When a line outage is simulated, results show that the DGs reactive power generation and supply the lost generation. Here, the DGs also help to improve the dynamic voltage stability of the load buses. When an outage occurs close to a sensitive area, the whole system will be affected whereas, outage at load central area could not affect much the entire system stability.

Finally, three phase short circuit fault is more harmful in critical buses which may lead to system collapse if the protection system fails to isolate the fault.

In general, the results show that the occurrence of contingencies in power system is result in increasing of voltage drop in some of buses in the system.

\section{Future Work}

This project assumes two kinds of DGs which are diesel engines and wind power. But a more practical Microgrid may consist of different types of DGs such as PV power, etc. Also, the Microgrid can be connected to the main instead of islanded; this provides more accurate dynamic results. The utilities are moving towards smart grid technologies which include more information about the system variables in real time. In power system is not static but changes during operation (switching on or off of generators and transmission lines) and during planning (addition of generators and transmission lines). Supervisory Control and Data Acquisition (SCADA) system is playing a vital role in delivering power in a reliable and safe manner. SCADA system also supervises controls, improves and manages generation and transmission systems. Therefore, that it is possible to get online data. The voltage stability study carried out in this project is only relied on some steady state parameters. Unfortunately, this kind of analysis is limited to certain applications only such as offline power system planning and not suitable for instant dynamic events study.

\section{References}

[1] H. Chen, J. Chen, D. Shi, and X. Duan, "Power flow study and voltage stability analysis for distribution systems with distributed generation," IEEE, 2006.

[2] W. H. Kresting and R. C. Dugan, "Recommended Practices for Distribution System Analysis," in Proc. IEEE Power System Conf. Expo, Atlanta, GA, Oct. 2006.

[3] E. Bompard, E. Carpaneto, G. Chicco, R. Napoli, "A dynamic interpretation of the load-flow Jacobian singularity for voltage stability analysis," International Journal of Electrical Power \& Energy Systems, vol. 18, no. 6, p. 385395, August 1996.

[4] E.G. Carpaneto, G. Chicco, R. Napoli and F. Piglion, "A NR method for steady state voltage stability assessment," in Proc. Bulk Power Sys. Voltage Phenomenon Voltage Stability and Securit, 1991.

[5] M. Eidiani and M.H.M. Shanechi, "FAD-ATC, A New Method for Computing Dynamic ATC," International Journal of Electrical Power \& Energy Systems, vol. 28, no. 2, pp. 109-118, February, 2006.

[6] P. L. Jeffrey, "Modeling of Dynamic Loads for Voltage Stability Studies," Cookeville, 2007.

[7] P. Kundur, John Paserba, Venkat Ajjarapu, Goran Anderson, Anjan Bose, Claudia Canizares, Nikon Hatziargyriou, David Hill, Alex Stankovic, Carson Taulor, Thierry Van custem, and Vijay Vittal, "Definition and Classification of Power System Stability," IEEE Trans. On Power System, vol. 19, no. 2, pp. 1387-1401, May 2004.

[8] F.A. Althowibi and M.W. Mustafa , "Voltage Stability Calculations in Power Transmission Lines: Indications and Allocations," in IEEE International Conference on Power and Energy (PECon2010), Kuala Lumpur, Malaysia, Nov 29 - Dec 1, 2010.

[9] M. Alinezhad and M.Ahmadi Kamarposhti , "Static Voltage Stability Assessment Considering the Power System Contingencies using Continuation Power Flow Method," International Journal of Electrical and Electronics Engineering, pp. 316-322, 2010.

[10] A. Jigar Pujara and G. Vaidya, "Voltage stability index of radial distribution network," in International Conference on Emerging Trends in Electrical and Computer Technology, Nagercoil, India, 23-24 March 2011.

[11] H. Saadat, Power System Analysis, New York: USA, 2004.

[12] F. Milano, "Documentation for PSAT 2.1.6," May 25, 2010.

[13] P. Kundur, Power System Stability and Control, McGrawHill, 1994.

[14] L. L. Grigsby, The Electric Power Engineering Handbook, 2nd ed., CRC, 2007. 